\title{
The Role of the Teaching Context in Hong Kong English Teachers' Perceptions of L2 Writing Pedagogy
}

\author{
Sima Sengupta \\ Department of English, Hong Kong Polytechnic University, Hung Hom, Hong \\ Kong
}

\section{Peter Falvey}

Department of Curriculum Studies, University of Hongkong, Pokfulam Road, Hong Kong

This paper examines the ways in which L2 writing is perceived and its pedagogy conceptualised by English language teachers in Hong Kong secondary schools. It then attempts to delineate the factors that shape teacher perceptions. Data for this study were gathered through a questionnaire survey, which was followed up by teacher interviews, classroom observations, written protocols and documentary analysis. These data indicate that the perceptions of Hong Kong language teachers regarding students' L2 writing are dominated by language-related concerns at the sentence level with minimal focus on either the discourse-related or cognitive aspects of writing. Grammatical and lexical errors engage maximum teacher attention. The data suggest that teachers' perceptions of L2 writing are predominantly shaped by the contextual factors that surround their classroom lives. It is argued that conditions for teacher perceptions will be subject to change as the context becomes more sensitive to the discourse-related and cognitive factors within $\mathrm{L} 2$ writing that recent developments in curriculum renewal and language teacher education in Hong Kong are likely to bring.

\section{Introduction}

It is well recognised in writing research that cognitive and contextual factors shape the teaching and learning of writing (see for example, Flower, 1989; Nystrand et al., 1993; Silva, 1993). Within this social/contextual dimension, a writing task is perceived not as a writer's private expression but as evidence of the ways in which writers negotiate the social context, create their own goals, and develop a sense of self as belonging to a community (Flower, 1989:284). Context, as argued by Flower (ibid: 287), 'in many ways determines, directs, or prompts the kind of thinking the individual writer will do'.

However, how cognition and context interact in the classroom is not yet well documented (Flower, 1989: 282). This paper describes an exploratory investigation that examines how cognition and context influence teacher perceptions of the classroom teaching of second language (L2) writing. In investigating teachers' thoughts, practices and beliefs about writing pedagogy, the paper explores the question of how these beliefs are acquired, justified and explained by the teachers in the sample and what social and cognitive implications these justifications have for curriculum development.

The paper will begin with a brief review of the field of English as a Second Language (ESL) writing in order to provide a broad context for the reader. This 
is followed by an introduction to research in writing conducted in Hong Kong to provide specific background to this study. The methodology of the study is then described with a broad overview of the Hong Kong school context. Findings are then presented. Arising out of these findings, the paper then discusses possible factors, both social and cognitive, that seem to shape and determine what goes on in the writing classrooms in Hong Kong. The paper ends with a description of factors which may contribute to change in the context in which the classroom teaching of writing in Hong Kong takes place. These changes include: a new examination syllabus; the introduction and implementation of a wholly new curriculum and its associated assessment mechanisms; legislation to ensure a fully professionally-qualified teaching force; and the introduction of language benchmarks for teachers of English. All four changes, it is argued, may provide the contextual conditions for potential change from the current accuracy-focused L2 writing classroom described below into a more discourse-related, cognitively aware classroom.

\section{Research Background}

This section first discusses how L2 writing has been investigated and how the findings inform L2 pedagogy both outside and in Hong Kong. Teacher beliefs and knowledge are then briefly discussed.

\section{Research into composition}

Researchers such as Raimes (1985, 1986, 1987, 1991); Zamel (1983, 1984, 1985, 1987); and Silva $(1989,1990,1993)$ have contributed to the understanding of L2 writing by demonstrating to L2 writing researchers and teachers the kinds of constraints that writers must juggle with and the strategies they must orchestrate to produce an effective text. For example, Raimes' research (1985) makes it clear that second language writers need to learn:

- how to be aware of and make use of the processes involved in their writing;

- how to develop and organise their ideas; and

- how to deal with language related concerns.

Successful writers do not just string sentences together. They employ a variety of strategies in individual ways as part of a recursive composing process as Emig's (1971) ground-breaking research clearly demonstrated. Emig's research, which was followed by other studies (cited above), helped to provide an understanding of the writing process. They should have had far-reaching implications for teachers, teacher educators and the teaching of writing because these studies showed that there is much more to the teaching of successful writing than the mere teaching of accuracy in lexis and syntax.

\section{The minimal effects of research on pedagogy}

However, in spite of the implications of process research, it has been found that it has had minimal impact on the teaching of writing since, in spite of research evidence (Ammon, 1985; Urzua, 1987), teachers often teach students mainly surface-level features of writing. It has been pointed out by researchers, such as Shuy (1981: 127) and Raimes in L2 (1983: 259), that at the school level writing 
teachers often concentrate on the teaching of grammatical rules at the expense of other areas of writing. As Zamel notes:

It seems that ESL writing teachers view themselves primarily as language teachers, that they attend to surface-level features of writing, and that they seem to read and re-act to text as a series of separate pieces at the sentence level or even clause level, rather than as a whole unit of discourse. (Zamel, 1987: 700)

These and other experts maintain that for both L1 and L2 learners, the teaching of grammar has an important role to play in the composition classroom (see Widdowson, 1983: 47; Raimes, 1986: 9) because writing is an artefact which has to meet certain standards of social acceptability (Widdowson, 1983). Indeed, Freedman (1986: 164) argues that enabling even L1 students to write grammatical sentences remains a challenge for teachers. However, a focus on grammar does not rule out a concomitant focus on discourse.

\section{Possible constraints within L2 writing}

The learning and teaching of writing in a second language is seen as doubly difficult since the linguistic constraints add to the complexity of the task (Widdowson, 1983: 47) and might often mean that writers in a second language attend to linguistic concerns from the very beginning, unlike their first language counterparts who seem to deal with language only after the initial ideas are articulated (Shuy \& Robinson, 1990). Added to these linguistic constraints are the numerous contextual constraints imposed by the classroom and the school. In a place like Hong Kong, many findings regarding the effective teaching of writing from other countries have limited applicability (see for example, Ammon, 1985; Urzua, 1987). Ammon (1985: 81) speaks of two effective writing lessons where the two separate ESL teachers were able to achieve breadth of instruction 'without sacrificing the depth' (p. 81). This, Ammon feels, was possible by individualising instruction. In his study, children were involved in activities that addressed their own particular needs. These classes consisted, on average, of nine children (p. 66). However, such practices in Hong Kong classes containing over 40 students would be difficult to imagine.

\section{Hong Kong secondary schools: Writing}

The context of second language teaching in Hong Kong is primarily teacher dominated and product-centred (Sengupta, 1996). Mahon (1992: 74) and Tse (1993) point out that even at primary level, there is an overwhelming demand for pupils to produce compositions that display the ability to accurately manipulate both language and mechanics. Such demands may lead to a situation where students are unable to pay attention to ideas and meaning. At secondary level too, researchers argue that writing is taught in a product-centred fashion (Pennington \& Cheung, 1995; Cheung, 1996). Cheung (1996) investigated the possibility of introducing a process approach as an innovation within the existing school curriculum in Hong Kong and found that the barriers to implementation, often cited by teachers, were problems such as class size, a tight time schedule, lack of resources, student standards, lack of motivation and the need for training. 
Tse (1993: 301), in his study of both L1 and L2 composing processes at primary schools, found that, on the whole, in both Chinese and English, writing was tested not taught.

It appears that assessment seems to rule the curriculum in Hong Kong. Issues of assessment take precedence over the curriculum. Biggs (1995), in discussing the dominance of assessment over the curriculum states:

The role of school-as-selection-device was particularly evident in the Hong Kong educational system from early days (Biggs, 1993), but it is not dead yet ... Assessment practices in Hong Kong are still geared towards providing data with which to select students: not only in the HKCE (Secondary 5) and HKAL (Secondary 7) examinations for tertiary selection, but in primary school, to provide data for banding in the Secondary School Places Allocation exercise. We may live in an age of electronic learning, but our assessment practices are driven by steam.

However, there is some evidence of a climate for change. The introduction of the Target Oriented Curriculum (TOC) and its more qualitative, non-mechanistic assessment practices into all primary schools in Hong Kong in 1996, together with a massive influx of financial resources for training and support mechanisms for teachers, may provide an opportunity for changes in approaches to teaching, learning and assessment. In spite of the relative failure of implementations such as communicative language teaching, the means for accomplishing change rest primarily in the washback effect that changes to assessment practices accompanying the introduction of TOC will inevitably bring. Morris (1995) states that:

The main purpose of assessment in Hong Kong has been to grade pupils and select them for further education and employment. Assessment of the attainment of individual pupils has been primarily carried out through formal public examinations. These examinations have ... a powerful influence on the style of teaching and learning used in schools ... The importance and influence of public examinations throughout all levels of schooling is therefore very substantial. (1995: 44-45, our italics)

The washback effect of TOC assessment and the introduction of an experiential dimension into the targets that have been set for English means that opportunities for expression through writing will be provided, issues of genre introduced, and the process of writing used as both a learning and assessment tool (Harris \& Mahon, 1997).

\section{Teacher beliefs and perceptions}

This paper describes teacher perceptions and beliefs, which are often shaped by teachers' existing knowledge, and how the teaching context helps support and extend that knowledge. In curriculum practice, Cornbleth (1990: 33) points out that there is a persistent interplay of contextual influences including teacher beliefs, the condition of classroom teaching, school and district goals and policies, and the community milieu. Beliefs 'appear to influence both what teachers choose to teach and how they choose to teach it' (Grossman et al., 1989: 31). Grossman et al. assert that the point of demarcation between beliefs and knowledge is blurred 
since, for philosophers, belief is the operative word in the definition of knowledge (1989: 31, footnote). Indeed teachers have a variety of sources from which to construct their knowledge of the teaching of a specific subject (see Grossman, 1990, for example). Amongst these sources, the educational context must play an important role. In research on teacher knowledge a distinction is made between teachers' knowledge of the subject matter (content knowledge) and knowledge of how to teach the subject (pedagogic content knowledge). Researchers maintain (see for example, Borko \& Putnam, 1994; Grossman, 1990; Shulman, 1986) that pedagogic content knowledge includes content knowledge as well as an understanding of the following:

- learners' preconceptions and misconceptions;

- the curriculum; and

- alternative curricular materials for a given subject or topic.

This study, in tapping teachers' perceptions of writing pedagogy, attempts to examine the factors that shape pedagogic content knowledge.

\section{Methodology}

\section{Research questions}

Within the broad aims of examining teacher perceptions, this study posed the following questions:

(1) What is/are the central aspect/s of writing pedagogy that Hong Kong teachers refer to when discussing writing?

(2) How do teachers rationalise their perceptions?

\section{Background: The broad context of Hong Kong secondary schools}

English language plays a unique role in Hong Kong. It has been described as an auxiliary language (rather than a foreign or second language $)^{2}$ in the sense that it is a non-native language reserved for certain restricted functions in society and for use by a restricted section of that society (Luke \& Richards, 1982: 55). English is the declared medium of instruction in most secondary schools although a mixed code of Cantonese and English has been the predominant style of presentation (Education Commission report No. 4 [ECR 4]). ${ }^{3}$

English is offered as a school subject at the beginning of six years of primary school. The teaching of writing begins at the primary stage. In the five years of secondary schooling, reading, writing, speaking and listening skills are developed and, at the end of five years, all students take the Hong Kong Certificate of Education examination (HKCEE), which tests all four skills. ${ }^{4}$ The composition paper accounts for $25 \%$ of the grades. The classroom teaching in secondary schools at the secondary 4 and 5 levels $^{5}$ (Grade 10-11) is very examinationoriented, examinations 'dominating style and content of learning in the classroom' (Report of the Visiting Panel, 1982: 33). The schools, often located in noisy urban areas, have small, crowded classrooms, containing more than 40 students and one teacher with no aides. Noise levels are such that many teachers can only be heard with the assistance of a microphone and amplifier. Schools are streamed 
by student levels of academic achievement (bands) but within each band, and even within each class, the language proficiency of students may vary widely.

\section{How data were gathered for this study}

Data were gathered in stages, starting with a survey (see Appendix 1 for questionnaire design and sample for the instruments) and then a number of follow-up instruments. The survey provided baseline data for understanding the concerns of the teachers in the writing classroom, which were then further explored by:

- loosely structured key informant interviews;

- documentary analyses of composition exercise books;

- documentary analyses of departmental papers;

- written protocols of teachers who were writing about their writing classrooms; and

- classroom observations and retrospective interviews.

The rationale for the follow-up was to understand, in greater depth, the responses to the questionnaire as well as to obtain a more extensive picture of individual representations and context-specific aspects of writing pedagogy.

\section{Analysis of data}

(1) The questionnaire data were analysed with the use of SPSS computer software and simple descriptive statistical analysis was performed. Descriptive statistics were seen as adequate for this portion of the study.

(2) The key informant interview data consisted of audio recording of the interviews (subject to the consent of interviewees) or the taking of broad field notes. The following constructs for the interview arose from the research questions:

(a) aspects of writing which Hong Kong teachers mention most often when discussing the teaching of writing;

(b) the rationale that Hong Kong teachers provide for their perceptions.

(3) The classroom observations and retrospective protocols, which followed the key informant interviews, were described in terms of how teachers dealt with the aspects of writing that they mentioned most frequently and how their classroom techniques matched the rationale they provided.

(4) The write-about protocol texts were tabulated in terms of the most commonly used techniques in the classroom and justification for the use of those techniques.

(5) The exercise books of 20 teachers were checked against a grid containing 12 constructs that arose from the data.

(6) The departmental papers (such as guidelines to teachers) were studied to understand the marking scheme and list the common factors that are mentioned. (Appendix 2 contains examples of all analyses and respondent profiles.)

\section{The sample}

Initially, the survey used a non-probability sampling method of convenient 
sampling. The sample, at this stage, consisted solely of teachers attending either an in-service, part-time certificate of education course in the faculty of Education in the University of Hong Kong or of teachers attending a refresher course at the same Faculty. Sixty participants took part in the two pilots. As the survey moved into its second and third year, a component of probability sampling was introduced by sending the questionnaires to a random selection of schools. At the time of the final analysis for this study, approximately $25 \%$ of the response sample consisted of the latter group (probability sampling). In total, 243 responses to the questionnaire had been received ( $37 \%$ response) at the time of the analysis. The sample for the other instruments was drawn from the survey respondents (see Appendix 1).

\section{Findings}

\section{Grammatical and lexical accuracy}

Grammatical and lexical accuracy is the most commonly mentioned aspect of writing that Hong Kong teachers refer to when talking about the teaching and learning of writing (see Appendix 2 for data summary). The teaching of writing is geared towards teaching how to write correct sentences. An examination of student exercise books indicated that teachers, red pen in hand, mark every single grammatical error on all 40 compositions and then mark the corrections, and then the re-corrections. The number of errors play a major role in the teacher determining the quality and acceptability of a composition written by a student. This phenomenon was also reflected in the classrooms observed, where either every student idea written on the board was made grammatically correct or where some grammar input was provided through questioning or lecturing. Underlying these practices is the perception of the centrality of grammatical errors, which seemed to arise largely from the teaching context. The following section will demonstrate this.

\section{Error-free writing}

This perception of accuracy as central to all discussions of writing is reflected in English teachers' concern for syntax. Table 1 summarises some of the survey responses regarding the importance of grammatically correct writing.

Table 1 Some findings about the importance of grammatically correct writing

\begin{tabular}{|l|c|}
\hline Items & Responses \\
\hline Teachers believe that the most common errors are grammatical & $72.4 \%$ \\
\hline $\begin{array}{l}\text { Teachers believe that a composition with many errors is } \\
\text { unsatisfactory even if the content and organisation are good }\end{array}$ & $60.5 \%$ \\
\hline $\begin{array}{l}\text { Teachers believe that writing involves creating correct sentences, not } \\
\text { good ideas that are expressed in inaccurate language }\end{array}$ & $42.3 \%$ \\
\hline $\begin{array}{l}\text { Teachers believe that all errors in a composition must be corrected } \\
\text { Teachers give grammatical accuracy maximum importance in writing }\end{array}$ & $56.4 \%$ \\
\hline
\end{tabular}


These responses were not confined merely to the questionnaire. They were borne out also in the documentary analysis of departmental papers and exercise books. The school departmental papers often advised teachers to mark for content, organisation and language. However, 9 out of 11 sets only described how to deal with language. The remaining 2 only provided a few lines on relevance and logic. The interviews and written protocols also showed an overarching concern for the use of language in written work in the English class. In the written protocols, exasperation with grammatical errors was mentioned by 24 teachers. However, English teachers who teach content subjects (in English) seem to hold an entirely different philosophy. This is made apparent in Extract 1, which seems to signify that teachers do not perceive language as a way of realising meaning across the curriculum.

\section{Extract 1: Differences in the way writing is viewed for other subjects}

R: You said you teach history as well. Aren't students required to write essays in History?

T: Yes but that is different.

R: How?

T: Because there the errors don't matter - we only tick the points and mark on the points and ignore the language.

R: Even if the point is expressed in ungrammatical language and you don't understand it?

T: Yes, ungrammatical is not important — it is History not English — if the keywords are there then it is okay.

\section{Errors and ideas}

On the issue of idea generation, teachers in the sample reported that they facilitated idea generation in their classrooms. There was allusion to questioning and class discussion of topic in $90 \%$ of the written protocols. $45 \%$ of the teachers interviewed mentioned idea generation and there was evidence of facilitating idea generation in all the classrooms observed. Yet, they did not talk about language as a tool for making meaning. The generation and organisation of ideas were not seen as a problem by the majority of teachers in the sample. For them, the problem was expressing the ideas in 'correct' language. The quality of the idea was not seen as central to their jobs as English teachers. They seemed to believe that syntactic maturity was the first step in writing and this maturity was manifested in terms of how 'correct' the sentences in student compositions were. Although they did not directly downplay the role of ideas, one teacher in the written protocol wrote 'I mark every error and give feedback on common errors because I don't know if their ideas are good unless I understand what they are trying to say'. The documentary analysis revealed that many schools follow a tripartite marking scheme for composition. The three separate categories are language (referring to accuracy), content and organisation. Among the teachers interviewed, 17 teachers said that at secondary school level ideas were essentially similar and the quality of a composition was not particularly affected by ideas. Extract 2 below, from two interviews, shows how language is the predominant concern. 


\section{Extract 2: Language and content}

\section{Extract A}

R: Yes - so you do not look for the quality of ideas?

T: I first look for the language - I think to us - to Hong Kong English teachers - errors are very important - it is our way - we are very upset by errors - we think errors really give a bad impression - you know I think if any Chinese teacher says that they don't - that she doesn't mind errors as long as the content is good - then they are not Hong Kong people. Are you surprised?

\section{Extract B}

T: $\quad$... good writing is when the message is clear and bad writing - say when there are so many errors that there is no message. Is my definition wrong?

R: Of course not. I think it is reasonable to say that the message must be clear. What, would you say, makes this message clear?

T: To a certain extent handwriting; also the knowledge of the language, i.e. spelling, vocabulary, grammar, you know things that help you make sense of the ideas.

\section{Discourse-related errors}

The facet of written work called 'organisation' was given some recognition in the composition marking scheme described above. This is an attempt to recognise the discourse-related factors in student writing. However, 'organisation' seemed to be a rather rigid definition in the respondents minds. ${ }^{6}$ When teachers were asked to elaborate their interpretation of 'organisation' in the interview stage, it was clear that aspects such as logical sequencing of ideas, appropriate strategies for developing ideas, rhetorical patterns of different kinds of writing or the ways in which specific rhetorical patterns will serve the writing purpose and affect the audience were not considered as part of 'organisation'. As Extract 3 indicates, they were not seen as essential aspects of writing worthy of an investment of time either at the teaching ${ }^{7}$ or feedback stage.

\section{Extract 3: Interpretation of organisation}

\section{Extract A}

R: Do you think just telling students the basic structure (introduction, body, conclusion) is enough?

T: Yes it is. Our students are weak - we cannot confuse them with too much!

R: Do you ever show them how ideas are organised in a reading passage or how writers can develop ideas?

T: Believe me Sima, I'd love to do all this - but ask the school to give me more than eight lessons a week and less than three forms. It is just not possible with lower forms and also the benefits of doing such things are questionable... 


\section{Errors and feedback}

The narrow definition of errors described above was also evident in the data taken from exercise books. Errors were viewed as surface-level problems, unrelated to discourse in general. ${ }^{8}$ There was often evidence of teachers being, in Zamel's words:

so distracted by language related problems that they often correct these without realising that there is a much larger meaning-related problem that they have failed to address'. (Zamel, 1987: 700)

The emerging picture from analysis of the exercise books suggested that students received their compositions marked in red, looked at the codes and tried to understand the grammatical ${ }^{9}$ problems. They then wrote the correct version in pencil before writing up a fair copy. Often the errors remained intact and there was evidence of multiple re-corrections in nine cases in lower forms.

\section{How teachers justify their perceptions of the centrality of errors in L2 writing}

In justifying their concern with linguistic errors, teachers often referred to the contextual factors arising from institutional, social and curricular practices as described below. Yet tied into these contextual factors, we see a dynamic interaction between cognition and context. Teachers' pedagogic content knowledge seems to be shaped not only by their knowledge of the subject matter and knowledge of the curriculum, students and materials, but also by the curricular context in which they operate. ${ }^{10}$

\section{Institutional factors: Teacher support}

Of the survey respondents, $97.1 \%$ stated that the English panel chairpersons (departmental heads) in their schools require teachers to ensure students complete a minimum number of compositions with each class. This minimum number is usually 10 to 12 compositions a year for each form. The panel chairperson is responsible for ensuring that teachers get students to complete these writing tasks adequately. As part of this checking system, the panel chairperson checks the exercise books at the time of the annual appraisal of teachers. It appears from analysis of the work of students that this requirement of minimum numbers is counter-productive - very little progress is made.

A potential solution to this problem may be for a panel chair to provide a collaborative working environment where teachers are introduced to recent advances in writing pedagogy and encouraged to take the initiative to reflect upon newer ideas and share them with their colleagues. Indeed, we maintain, for progress to be made, the panel chair's responsibility, currently mainly administrative, should be geared towards staff development.

\section{Institutional factors: Top-down curricular practice}

Each form is also required to write a minimum number of words for each of the compositions they complete. In the classrooms observed, every teacher reminded the students of this requirement - writing the number of words on the board. In the documentary analysis of exercise books, the effect of the minimum word requirement was clearly visible. In approximately $10 \%$ of the 
books examined, there was widespread evidence of laboured counting of words. Words were counted and written down as lines or paragraphs were completed. Most teachers interviewed felt that a minimum number of compositions and words ensured some kind of standardised practice and prevented lazy teachers and students from doing less work. The possibility that requiring a minimum also means setting a maximum, as pointed out by Au Yeung (1991: 106), did not seem to worry teachers.

Some teachers, however, perceived a dissonance in this 'minimum number of words' situation. They seemed to think that such a requirement would mean worse quality because students will 'fill it up with rubbish'. Yet the belief was expressed that writing more would help by providing more practice. The teachers interviewed seemed to believe that more is the keyword. This idea has also been expressed by Raimes (1985: 250). However, her concept of more refers to the need for a variety of writing activities. This is different from the teachers in the sample for whom more words was one viable way of ensuring that students complete more and teachers 'correct' more within the limitations imposed by teacher workload. However, is it possible that these limitations are artificially created by the top-down curricular practices of setting rules and regulations that do not encourage alternative ways of viewing writing? ${ }^{12}$

\section{Examination}

The public examination clearly was the guiding force (see Morris, 1990: 56). Every teacher interviewed mentioned the examination, irrespective of whether or not they taught the examination classes, i.e. Secondary 5 and 7 (Grades 11 and 13). On the issue of the need to write a minimum number of words, many felt that it is a necessary evil. Almost $50 \%$ of the teachers interviewed pointed out that unless minimum word limits were set, students would never be able to write a 300-word composition for HKCEE because, as a rule, their students wrote very short compositions. Indeed, the HKCE examination influenced perceptions of other aspects of writing pedagogy. For example, though the majority of the survey respondents disagreed with the statement that reader awareness was not necessary at HKCEE level, the mental configuration of a 'reader' did not go beyond the HKCEE marker for the Form 4 or 5 compositions. ${ }^{13}$ The way teachers described their writing classrooms clearly indicated that very little time was spent on teaching writing. In contrast, considerably more time was spent on testing writing by correcting the product and giving a grade or marks for each piece of writing.

In fairness to the examination authority, it should be noted that within the examination-dominated context of Hong Kong, the Hong Kong Examinations Authority (HKEA) attempts to provide a positive washback effect through changes to the examination syllabus, which included, in 1996, the introduction of a new English language syllabus. The syllabus introduces an integrated-skills examination paper, forcing teachers to take a more integrated approach to teaching and learning.

Tse (1993) points out that in Hong Kong, studying to pass examinations is the norm and the teaching of writing is very examination oriented. Almost all compositions are done in the classroom and, in many respects, are considered tests (p. 301). Hitherto, teachers seemed to be unable or unwilling to differentiate 
between teaching and testing unless such differentiation was recognised by the school principals and pointed out to teachers.

\section{Teacher awareness of written discourse}

An examination of teacher beliefs about writing and its teaching in relation to other skill areas indicates that a large number of respondents $(40 \%)$ in the sample believed that writing was the most difficult and frustrating skill to teach. The question was whether there were cognitive as well as contextual factors that shaped these responses. Survey responses indicated some awareness of process and discourse-related factors. For example, 63.4\% disagreed with the statement that writing is a step-by-step process involving thinking, then planning, then writing, and lastly revision; $25.1 \%$ believed that using connectives such as 'moreover' is the best way to ensure coherence; ${ }^{14}$ and $22.6 \%$ thought that coherence and cohesion are the same thing. These responses were further probed in the interviews and retrospective protocols (following classroom observations), and it seemed clear that teachers seemed to have only a vague understanding of what the writing process involved or how discourse-related issues can be taken into account in the classroom. In retrospective interviews after the observations, five out of seven teachers said that they did not know anything about the concept of macrostructure of text or of rhetorical structures. They often seemed to believe that the only way the writing process could be taken into account in the classroom was to follow a 'process approach', which, for them, meant a focus on fluency at the expense of accuracy.

This is indeed understandable as research into the teaching of writing is a comparatively young field (Deggenhart et al., 1992: 94) and, since second language writing field is even younger (Silva, 1993: 668), teachers are likely to bring into the classrooms their own interpretation of the unique nature of L2 writing. It has been observed by researchers looking at composition teaching in 19 countries (Deggenhart et al., 1992) that,

Clearly, then, teachers in various systems in the study differ as to the paramount concern influencing their various activities. The differences, however, are not marked by the ideological differences that appear in the literature surrounding composition teaching. As in other areas of the curriculum, the real concerns of teachers are more pragmatic than ideologi$\mathrm{cal}^{\prime}$. (p. 99)

In spite of Deggenhart's views, we, as teacher educators, believe that these 'pragmatic concerns' may still be influenced by an awareness of the nature of writing. Such an awareness will be facilitated if the curriculum presents a broad view of writing. It will be further facilitated if this view is situated within the complex maze of factors that determine teacher perceptions of the benefits, rather than the costs of allowing newly-acquired awareness or beliefs to filter into day-to-day practice. Indeed, if teachers are encouraged and helped to build on their existing knowledge of written discourse and writing pedagogy, their perceptions of the salient aspects of writing pertaining to their classrooms are likely to change. We hope that this process of change is taking place or about to take place in Hong Kong. 


\section{Discussion}

The evidence presented above shows, in particular, two sets of teacher beliefs that, we maintain, militate against theoretically sound L2 writing practice. The first is a focus on lexical and syntactic features of writing with a concomitant deleterious effect on the teaching of discourse-related and cognitive features of writing. The second is the inability of examination-focused teachers to separate teaching from testing. This study indicates that the latter set of beliefs creates a climate in which most L2 writing in the secondary school is geared towards regular school or public examinations, resulting in mere practice of the product without the pedagogic support of learning how to construct the product. In describing how the existing context shapes English teachers' perception of the teaching and learning of writing in terms of the linguistic errors in the product, we have argued that these contextual factors arise from constraints laid by institutions, examinations and teachers' existing knowledge base (see Figure 1).

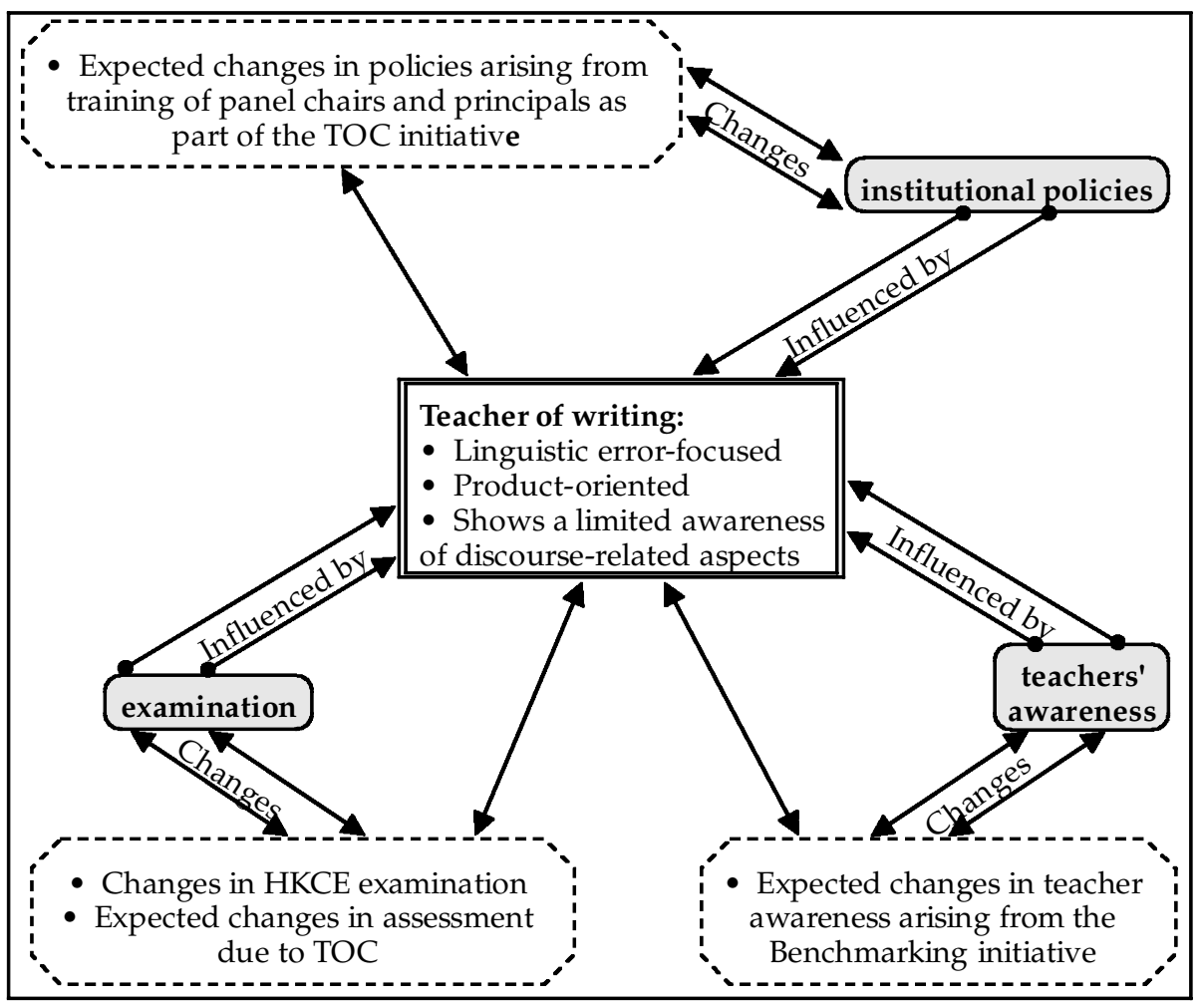

Figure 1 How the changes are likely to affect the teaching of writing

In this section, the potential impact of changes in the system will be discussed in relation to these widely-held beliefs, which invariably affect writing pedagogy. As Figure 1 indicates, changes in the system (in dotted boxes) will change the constraints that shape classroom practice. Firstly, the objectives of TOC, already introduced into primary schools, will be followed by its introduction into secondary schools at the turn of the century. This will mean that teachers will be 
encouraged to use a task-based approach where the importance of the writing process and the discourse-related aspects of writing are recognised (Curriculum Development Council, 1994: 17). Secondly, and in addition, large amounts of public funding have been allocated to training for the new curriculum. Thirdly, in terms of a professionally qualified teaching force, by 2001 all teachers in Hong Kong will have to possess a formal teaching qualification (currently, possession of any degree allows a person to teach English in secondary schools). Lastly, in terms of language standards, all teachers of English within the next few years, will be benchmarked for language ability, subject content knowledge, pedagogical content knowledge and teaching ability (Coniam \& Falvey, 1996). Thus, it is reasonable to expect change. However, the changes depicted in Figure 1 will be reciprocal (as the two-sided arrows indicate). Not only will they affect the context of teaching, they will also be influenced and shaped by that very context. As a result, it is neither plausible nor reasonable to expect sweeping changes.

Indeed, it would be naïve to claim that new initiatives will solve all the problems described above, particularly as the history of curricular change is fraught with accounts of failure (see for example, Morris, 1995; Eisenberg, 1995). However, these new initiatives (especially those affecting changes in assessment practices with their inevitable washback effect on teacher behaviour) are bound to result in some change. The changes that occur initially may be small but they may be incremental changes that will accumulate over time (see Cheng (forthcoming), who has documented classroom behavioural change in line with changes in the new examination syllabus for English). Given the type, nature and quantity of the changes about to affect Hong Kong teachers of English, some change in pedagogy is inevitable, even though the process of change may be slow. Optimistic predictions of wholesale changes must be tempered by reality.

Our perception of this reality leads us to believe that the changed context, produced by the impact of these curricular initiatives, may create conditions that will allow for the development of a community of teachers with an awareness of how language works at the level of discourse and a familiarity with recent developments in language teaching, particularly, within the context of this paper, the teaching of L2 writing.

Hong Kong is now without the manufacturing base on which much of its early successes rested. Its economic success now depends largely on its burgeoning service industries. Such success requires continuing improvement in trilingual language skills (Chinese, Putongua and English). We maintain that it is important, both during and after the transition of sovereignty to China, that improvements in the teaching of writing are implemented (backed by the measures described above), together with other language improvement measures, to ensure that the people of Hong Kong possess the sophisticated language skills necessary to retain their place in the world's economy. Otherwise, as pessimists have predicted, Hong Kong may regress; in the process becoming a comparative backwater - merely another China coastal town.

\section{Notes}

1. The term 'Hong Kong' is variously represented as 'Hong Kong' or 'Hongkong'. 'Hong Kong' is usually used in the Territory but major corporations such as the Hongkong 
and Shanghai Banking Corporation conflate the two words. If authors cited in the text use the term 'Hongkong' it is retained. Otherwise the two words are separated.

2. There has been an on-going debate for some years about the status of English in Hong Kong. The notion of English as a second language (as in parts of Africa and India) has now been largely abandoned. Writing in 1982, 15 years before the handover of power, Luke and Richards suggested the term 'auxiliary language' to indicate the division between normal life and basic commerce where $98 \%$ of the population used Chinese (Cantonese) and the language of power (English) in the courts, international commerce and government. However, since the handover of power from the UK to China, the argument for the term 'English as a foreign language' has become more powerful - e.g. Chinese is now used in the courts, the laws are being translated into Chinese and the language used in the Legislative Council is now almost wholly Chinese.

3. After the publication of ECR4, in which it was suggested that less than $30 \%$ of secondary school students could benefit from being educated through the medium of a language other than their mother tongue, a concerted move towards mother-tongue education was promoted.

4. However, another change for the better will occur in 1996 when a new syllabus that promotes a more integrated approach to teaching and examining is introduced (see Cheng, 1996).

5. The Hong Kong education system is similar to the UK where six years of primary schooling is followed by five years of secondary and then two years of senior secondary.

6. Of the survey respondents $56.4 \%$ believe that 'good organisation' means an introduction of a paragraph, a two or three paragraph body and a one paragraph conclusion. In the written protocols, 16 out of 30 respondents mentioned 'organisation' in terms of 'introduction, body and conclusion'.

7. This confirms previous findings of other researchers such as Mohan and Lo (1985) who have commented on the Hong Kong students belief that they had not learned to organise essays sufficiently well (Mohan \& Lo: 527). Siu (1986), had looked at argumentation and concluded that students in schools of Hong Kong were not being consciously taught rhetorical skills.

8. For example, in secondary 4 compositions, on the dangers created by illegal hawkers, a topic that was set by three of the teachers whose exercise books were analysed, a similar grading pattern was discerned. Teachers had corrected the surface-level errors in sentences but ignored the fact that some students who had described all hawkers in general at the beginning had focused on specific dangers related to food hawkers without signalling this focus to the reader. Thus, the fact that students had used the word 'hawkers' to mean different kinds of hawkers in different parts of the composition was not seen as problematic .

9. This includes lexical errors.

10. The importance of context is recognised by Grossman (1990). However, its centrality is not discussed.

11. The panel chairs in the sample were attempting to build in such a definition of their role.

12. Teachers did not think highly of alternative ways of writing more such as keeping a journal or doing a collaborative writing project, as suggested by the researchers, since to them practice entails that a piece of writing is corrected?

13. These perceptions are similar to the views expressed by Hong Kong students (see Sengupta, forthcoming).

14. In ESL, a common problem is the over-teaching of connectives as a 'quick fix' to coherence-related problems (Ferris, 1994).

\section{References}

Ammon, P. (1985) Helping children learn to write on English as a second language: Some 
observations and some hypotheses. In S.W. Freedman S.W (ed.) The Acquisition of Written Language (pp. 65-84). Norwood, NJ: Ablex.

Au Yeung, Y.C. (1991) Personal writing: An alternative approach to teaching writing to secondary students. New Horizon 32, 105-7.

Biggs, J. (1995) Assumptions underlying new approaches to educational assessment: Implications for Hong Kong. Curriculum Forum 4 (2), 1-22.

Biggs, J. and Watkins, D. (eds) (1993) Learning and Teaching in Hong Kong: What Is and What Might Be. Education Paper 17, Faculty of Education, University of Hong Kong.

Borko, H. and Putnam, R.T. (1995) Expanding a teacher's knowledge base. In T.R. Guskey and M. Huberman (eds) Professional Development in Education (pp. 35-65). New York: Teachers College.

Cheng, L.Y. (Forthcoming) How does washback influence teaching? Implications for Hong Kong. Language and Education 10 (1).

Cheung, M (1996)Implementing process writing in Hong Kong secondary schools: A case study of the effect of an innovation-related in-service programme on the process and outcomes of teachers' adoption. Unpublished PhD thesis. City University of Hong Kong.

Coniam, D. and Falvey, P. (1996) Setting language benchmarks for English Language teachers in Hong Kong secondary schools. Final report for The Advisory Committee on Teacher Education and Qualifications (August). Hong Kong: Hong Kong Government.

Cornbleth, C. (1990) Curriculum in Context. London: Falmer Press.

Curriculum Development Council (1994) Target Oriented Curriculum Programme of Study for English Language: Key Stage 1 (Primary 1-3) 1994. Hong Kong: Curriculum Development Council.

Deggenhart, R.E., Tormakangas, K., Purves, A.C. (1992) The community of teachers in written composition. In A.C. Purves (ed.) The IEA Study of Written Composition 11: Education and Performance in Fourteen Countries (pp. 87-102). Oxford: Pergamon Press.

Emig, J. (1971) The Composing Process of Twelfth Graders: National Council of Teachers of English Research Report No. 13. Urbana, Illinois: National Council of Teachers of English.

Education Commission Report No. 4 (1990). Hong Kong: Government Publication.

Eisenberg, J. (1995) The limits of educational research: Why all research and grand plans in education are futile and wasteful. Curriculum Inquiry 25, 367-80.

Ferris, D.R. (1994) Rhetorical strategies in student persuasive writing: Differences between native and non-native English speakers. Research in the Teaching of English 28 (1), 45-63.

Flower, L. (1989) Cognition, context and theory building. College Composition and Communication 40, 282-311.

Freedman, D.C. (1986) Linguistic and error analysis: On agency. In D.A. McQuade (ed.) The Territory of Language: Linguistics, Stylistics and the Teaching of Composition (pp. 165-73. Carbondale: Southern Illinois University Press.

Grossman, P.L. (1990) The Making of a Teacher. New York: Teachers College Press.

Grossman, P.L., Wilson, S.M. and Shulman, L.S. (1989) Teachers of substance: Subject matter knowledge for teaching. In M.C. Reynolds (ed.) Knowledge Base for the Beginning Teachers (pp. 23-36). Oxford: Pergamon.

Harris and Mahon. T. (1997) Writing and the use of literature in the English classroom. In P. Falvey and P. Kennedy (eds) Learning Language through Literature: A Source Book for Teachers of English in Hong Kong (pp. 9-28). Hong Kong: Hong Kong University Press.

Koziol, S. Jr (1982) Written Composing, Communication Skills. PCRP Assessment Survey. Eric document ED 213030.

Luke, K. and Richards J. (1982) English in Hong Kong: Functions and status. English Worldwide 3 (1), 47-64.

Mahon. T. (1992) From sentence to story: A process approach to the development of composition skills in the primary school. In M. Lau and M.J. Murphy (eds) Developing Writing: Purposes and Practices (pp. 74-87). Hong Kong: English Division, Institute of Language in Education, Hong Kong Government Publication.

Mohan, B.A. and Lo, W.A. (1985) Academic writing and Chinese students: Transfer and developmental factors. TESOL Quarterly 19 (3), 515-34. 
Morris, P. (1990) Curriculum development in Hong Kong. Education papers. Faculty of Education, University of Hong Kong.

Morris, P. (1995) The Hong Kong School Curriculum. Hong Kong: Hong Kong University Press.

Nystrand, M., Greene, S. and Wiemelt, J. (1993) Where did composition studies come from? Written Communication 10 (3), 267-333.

Pennington, M.C. and Cheung, M. (1995) Factors shaping the introduction of process writing in Hong Kong secondary schools. Language, Culture and Curriculum 8 (1), 15-34.

Raimes, A. (1983) Anguish as a second language: Remedies for composition teachers. A. Freedman, I. Pringle and J. Yalden (eds) Learning to Write: First Language/Second Language (pp. 258-72). Essex: Longman.

Raimes, A. (1985) What unskilled ESL students do as they write: A classroom study of composing. TESOL Quarterly 19 (2), 229-58.

Raimes, A. (1986) Teaching writing: What we know and what we do. (Eric Document Reproduction Service No. ED 271 030).

Raimes, A. (1987) Language proficiency, writing ability, and composing strategies: A study of ESL college student writers. Language Learning 37 (3), 439-68.

Raimes, A. (1991)Out of the woods: Emerging traditions in the teaching of writing. TESOL Quarterly 25 (3), 407-30.

Report of the Visiting Panel (1982) A Perspective on Education in Hongkong. Hong Kong: Government Publication.

Sengupta, S. (forthcoming) Peer evaluation: 'I am not the teacher'. To appear in ELT Journal $52(1)$.

Sengupta, S. 1996. A study of the effects of the systematic teaching of revision on the L2 learners in a secondary school in Hong Kong. Unpublished PhD thesis. Department of Curriculum Studies, University of Hong Kong.

Shulman, L.S. (1986) Those who understand: Knowledge growth in teaching. Educational Researcher 5 (2), 4-14.

Shuy, R.W. (1981) Toward a developmental theory of writing. In C.H. Frederiksen and J.F. Dominic (eds) Writing: The Nature, Development and Teaching of Written Communication Volume 2: Writing Process, Development and Communication (pp. 119-32). New Jersey: Lawrence Erbaum Associates.

Shuy, R.W. and Robinson, D.G. (1990) The oral language process in writing: A real-life writing session. Research in the Teaching of English 24 (1), 88-100.

Silva, T. (1989) A critical review of ESL composing process research. (Eric Document Reproduction Service No. ED 305820).

Silva, T. (1990) Second language composition instruction: Developments, issues and directions in ESL. In B. Kroll (ed.) Second Language Writing: Research Insights for the Classroom (pp. 7-23). New York: Cambridge University Press.

Silva, T. (1993) Towards an understanding of the distinct nature of L2 writing: The ESL research and its implication. TESOL Quarterly 27 (4), 657-77.

Siu, K. (1986) The effects of modes on syntactic and rhetorical complexity for ESL students at three grade levels. Unpublished Master's thesis. Chinese University of Hong Kong.

Tse, S.K. (1993) The composing process of Hong Kong children in primary schools. Unpublished PhD thesis. University of Nottingham.

Urzua, C. (1987) 'You stopped too soon': Second language children composing and revising. TESOL Quarterly 21 (1), 279-303.

Widdowson, H.G. (1983) New starts and different kinds of failures. In A. Freedman, I. Pringle and J. Yalden (eds) Learning to Write: First Language/Second Language (pp. 34-48). New York: Longman.

Zamel, V. (1983) The composing process of advanced ESL students: Six case studies. TESOL Quarterly 17 (2), 165-87.

Zamel, V. (1984) In search of the key: Research and practice in composition. In J. Handscombe, R. Orem and B. Taylor (eds) On TESOL '83: The Question of Control (pp. 195-207). Washington, DC: TESOL.

Zamel, V. (1985) Responding to student writing. TESOL Quarterly 19 (1), 4. 79-102.

Zamel, V. (1987) Recent research on writing pedagogy. TESOL Quarterly 21 (4), 697-713. 


\section{Appendix 1: Questionnaire Design and Sampling}

\section{Questionnaire Design}

To develop the questionnaire, a three-stage design approach was followed starting with a pre-design stage, then a design and piloting stage and, lastly, a post-pilot modification stage. At the pre-design stage, data were gathered through a focus group of practising teachers in a second year post-graduate certificate course and by exploring research into the teaching of writing in Hong Kong.

\section{Table A1}

\begin{tabular}{|c|c|c|}
\hline Constructs & Statements about & Source/reason \\
\hline Beliefs about writing & $\begin{array}{l}\text { Value of writing } \\
\text { What writing involves } \\
\text { What is good writing }\end{array}$ & $\begin{array}{l}\text { Other questionnaires used for } \\
\text { this purpose in USA (PCRP, } \\
\text { 1982). Comments of focus group }\end{array}$ \\
\hline Beliefs about teaching writing & $\begin{array}{l}\text { Interpretation of errors } \\
\text { Teaching of organisation } \\
\text { Teaching goals }\end{array}$ & $\begin{array}{l}\text { Classroom observations } \\
\text { indicated a lack of awareness } \\
\text { of what the teaching of writing } \\
\text { involves }\end{array}$ \\
\hline $\begin{array}{l}\text { Teacher awareness of writing } \\
\text { research }\end{array}$ & $\begin{array}{l}\text { Reading about writing } \\
\text { Attending seminars etc. } \\
\text { Reading syllabus } \\
\text { Metalanguage }\end{array}$ & $\begin{array}{l}\text { Focus group interviews, } \\
\text { observations of classes and } \\
\text { exercise books all pointed to a } \\
\text { certain lack of awareness, } \\
\text { which needed further } \\
\text { verification }\end{array}$ \\
\hline $\begin{array}{l}\text { Importance given to different } \\
\text { dimensions of the writing } \\
\text { process especially revision }\end{array}$ & $\begin{array}{l}\text { Content } \\
\text { Revision } \\
\text { Re-writing/follow-up } \\
\text { Organising } \\
\text { Planning }\end{array}$ & $\begin{array}{l}\text { The school departmental } \\
\text { papers often advised marking } \\
\text { for content, organisation and } \\
\text { language, but then only } \\
\text { described how to deal with } \\
\text { language }\end{array}$ \\
\hline Perception of linguistic errors & $\begin{array}{l}\text { Effect of error on task } \\
\text { Interpretation of 'error' } \\
\text { Accuracy vs. content } \\
\end{array}$ & $\begin{array}{l}\text { Examination of exercise books, } \\
\text { focus group members' similar } \\
\text { views about errors }\end{array}$ \\
\hline $\begin{array}{l}\text { Techniques used for teaching } \\
\text { writing }\end{array}$ & $\begin{array}{l}\text { Pre-writing input } \\
\text { Time spent } \\
\text { Methodology }\end{array}$ & $\begin{array}{l}\text { Focus group interviews, } \\
\text { observations, textbooks and } \\
\text { previous research in } \\
\text { process-oriented teaching in } \\
\text { Hong Kong }\end{array}$ \\
\hline $\begin{array}{l}\text { Techniques used for giving } \\
\text { feedback }\end{array}$ & $\begin{array}{l}\text { Beliefs about feedback } \\
\text { Use of comments } \\
\text { Discussion of problems }\end{array}$ & $\begin{array}{l}\text { Items chosen after examining } \\
\text { student exercise books and } \\
\text { studying departmental papers }\end{array}$ \\
\hline $\begin{array}{l}\text { Institutional requirements } \\
\text { regarding writing }\end{array}$ & $\begin{array}{l}\text { Number of words / tasks } \\
\text { Code for correction } \\
\text { Topic selection } \\
\text { Examinations } \\
\text { Time-tables }\end{array}$ & $\begin{array}{l}\text { Most of the items were chosen } \\
\text { after studying departmental } \\
\text { papers and speaking with a } \\
\text { number of panel chairs }\end{array}$ \\
\hline
\end{tabular}

In order to ensure reliability paired statements were used 


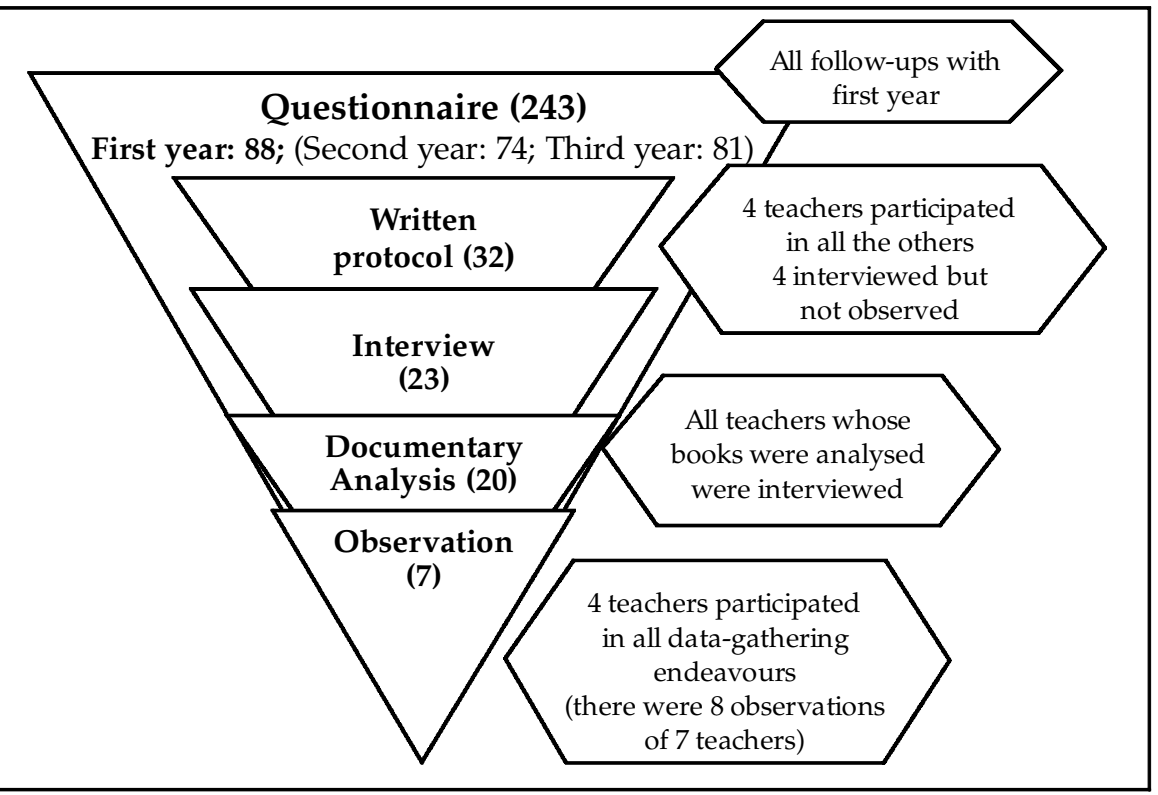

Figure A1 Sampling: The link between respondents

\section{Appendix 2: Data Summaries}

The following tables show the general profile of the respondents.

Table A2 Respondent profile for the questionnaire survey

\begin{tabular}{|l|c|}
\hline Description & Percentages \\
\hline Teachers teaching in aided Anglo-Chinese schools (English medium) & $72.0 \%$ \\
\hline University graduates & $74.1 \%$ \\
\hline Teachers who have attended INSTEP (in-service) courses & $25.5 \%$ \\
\hline Teachers with 4-2 years' experience in teaching English & $34.6 \%$ \\
\hline Teachers with 9-5 years' experience in teaching English & $23.0 \%$ \\
\hline Teachers with more than 10 years' experience in teaching English & $22.4 \%$ \\
\hline Teachers with experience outside Hong Kong & $9.5 \%$ \\
\hline Teachers attending PGCE or other courses at HKU & $76.8 \%$ \\
\hline
\end{tabular}

Table A3 Profile of the teachers interviewed

\begin{tabular}{|l|c|}
\hline \hline Description & Numbers (Total: 23) \\
\hline Teachers with more than 4 years experience & 11 \\
\hline Teachers with more than 2 years experience & 5 \\
\hline Teachers with more than 10 years experience & 3 \\
\hline Teachers with major in English & 13 \\
\hline Teachers working in Anglo-Chinese schools & 18 \\
\hline Expatriate teachers & 4 \\
\hline \hline
\end{tabular}


Table A4 Interview

\begin{tabular}{|c|c|}
\hline \multirow[t]{2}{*}{$\begin{array}{l}\text { Number of respondents } \\
\text { who mention this }(n=23\end{array}$} & $\begin{array}{l}\text { - Most common perceptions regarding errors } \\
{ }^{*} \text { Reasons (numbers mentioning reason in brackets) }\end{array}$ \\
\hline & Views regarding errors in writing \\
\hline \multirow[t]{6}{*}{21} & - Sentence errors most problematic and all must be corrected \\
\hline & ${ }^{*}$ my job, as an English teacher, is to teach correct English (19) \\
\hline & $\begin{array}{l}\text { * the more students practice correcting wrong sentences the } \\
\text { better it is for them (17) }\end{array}$ \\
\hline & ${ }^{*}$ HKCE marker will not understand/ will penalise (14) \\
\hline & ${ }^{*}$ I have no time to look beyond sentences $(9)$ \\
\hline & $\begin{array}{l}\text { * unless students write correct sentences how can they write } \\
\text { compositions consisting of many sentences }(8)\end{array}$ \\
\hline \multirow[t]{5}{*}{23} & - Grammatical errors most problematic and all must be corrected \\
\hline & $\begin{array}{l}\text { *I think grammar is most important to teach in all English } \\
\text { lessons (19) }\end{array}$ \\
\hline & ${ }^{*}$ my panel \& students expect that I correct all errors (19) \\
\hline & $\begin{array}{l}\text { * I am not aware of any other errors apart from grammatical } \\
\text { (10) }\end{array}$ \\
\hline & $\begin{array}{l}\text { * if I do not correct the errors they will think it is correct and } \\
\text { not see that it is wrong }(10)\end{array}$ \\
\hline \multirow[t]{6}{*}{19} & - Good composition determined by grammatical errors \\
\hline & ${ }^{*}$ I am supposed to correct all errors - it is my job (17) \\
\hline & ${ }^{*}$ my panel chair expects me to correct all errors (17) \\
\hline & $\begin{array}{l}\text { * ideas on a topic will be similar and so errors determine the } \\
\text { grades (15) }\end{array}$ \\
\hline & $\begin{array}{l}\text { * as a language teacher I must help students to express the } \\
\text { ideas in correct language so everyone understands (14) }\end{array}$ \\
\hline & * all my colleagues from F1-7 think so (14) \\
\hline \multirow[t]{4}{*}{12} & - Errors make most lasting impression on the HKCEE/AL grader \\
\hline & * all my colleagues who mark public exams say so (12) \\
\hline & * all English teachers think that (10) \\
\hline & $\begin{array}{l}\text { * in Hong Kong we want native speaker proficiency and } \\
\text { native speakers do not make mistakes ( } 8 \text { ) }\end{array}$ \\
\hline
\end{tabular}


Table A5 Written protocol

\begin{tabular}{|c|c|}
\hline $\begin{array}{l}\text { Number of respondents } \\
\text { mentioning }(n=32)\end{array}$ & $\begin{array}{l}\text { Categories mentioned } \\
\text { - Main propositions mentioned (numbers who mention each in } \\
\text { brackets) }\end{array}$ \\
\hline \multirow[t]{3}{*}{4} & Beliefs about good writing \\
\hline & - I think students must learn to write correct sentences first (2) \\
\hline & $\begin{array}{l}\text { - I think a composition full of errors is very frustrating for } \\
\text { teachers because it is a failure for teachers (2) }\end{array}$ \\
\hline \multirow[t]{4}{*}{5} & Views about student problems with writing \\
\hline & - students do not have the vocabulary (3) \\
\hline & - students do not have knowledge of grammar (5) \\
\hline & Input provided for writing: \\
\hline 5 & through other skill areas \\
\hline 21 & class discussion \\
\hline 29 & questioning \\
\hline 31 & providing grammatical guidelines \\
\hline 32 & providing vocabulary \\
\hline \multirow[t]{2}{*}{16} & $\begin{array}{l}\text { discuss organisation in terms of introduction, body and } \\
\text { conclusion }\end{array}$ \\
\hline & Techniques for giving feedback: \\
\hline 32 & correct grammatical errors \\
\hline 23 & write comments \\
\hline 7 & see weak students after school \\
\hline 24 & Grammatical errors most frustrating \\
\hline \multirow[t]{5}{*}{17} & Examinations and their effects \\
\hline & - my job is to prepare students for exams (8) \\
\hline & - my students expect exam practice (5) \\
\hline & - I choose topics for F4-7 from exam papers (5) \\
\hline & - students must get their grammar and vocab right for HKCE (4) \\
\hline
\end{tabular}


Table A6 Classroom observation: overall picture of classrooms before commencing writing

\begin{tabular}{|c|c|}
\hline $\begin{array}{l}\text { Number of respondents } \\
\text { who mention this }(n=23)\end{array}$ & $\begin{array}{l}\text { - Most common classroom practice } \\
* \text { Reasons (nubers mentioning reason in brackets) }\end{array}$ \\
\hline & Provide: \\
\hline 20 & - vocabulary \\
\hline 23 & • grammar \\
\hline 17 & - reminder on organisation: introduction, body and conclusion \\
\hline \multirow[t]{2}{*}{10} & - content: class discussion \\
\hline & Asked to: \\
\hline \multirow[t]{4}{*}{23} & - specify minimum number of words \\
\hline & ${ }^{*}$ essential for HKCEE (17) \\
\hline & * must not let students be lazy (15) \\
\hline & $\begin{array}{l}\text { * students want a word limit so that they know how much to } \\
\text { write (12) }\end{array}$ \\
\hline \multirow[t]{5}{*}{21} & - must complete minimum number of compositions \\
\hline & ${ }^{*}$ there is no time to do more $(18)$ \\
\hline & * the more they practice the better (17) \\
\hline & * must not let teachers be lazy (17) \\
\hline & Feedback: \\
\hline 21 & - three separate marks for composition \\
\hline 20 (for f4-7) 14 (for f1-3) & - count errors for giving grades \\
\hline 19 & - use code \\
\hline 23 & - marks: organization (10-20\% weight) \\
\hline 23 & - marks: ideas (20-25\% weight) \\
\hline \multirow[t]{2}{*}{17} & - claim that written feedback is provided \\
\hline & Teachers' beliefs about writing in schools: \\
\hline 15 & - writing is a matter of practice \\
\hline 16 & - students' linguistic standard is the main problem \\
\hline 18 & - student attitude is a problem \\
\hline 19 & $\begin{array}{l}- \text { good organisation is a composition divided introduction, } \\
\text { body and conclusion }\end{array}$ \\
\hline 14 & - pressures of HKCEE dictate what is taught \\
\hline 8 & - not given any thought to writing \\
\hline 11 & - in schools a teacher's goal is developing accuracy in writing \\
\hline
\end{tabular}


Table A7 Findings of exercise book analysis

\begin{tabular}{|l|c|}
\hline Constructs & Numbers \\
\hline Number of teachers using code & 16 \\
\hline Number of teachers writing comments for all forms & 6 \\
\hline Number of teachers writing comments for upper forms & 9 \\
\hline Number of rhetorical comments & 2 \\
\hline Number of grammatical rule-oriented comments & 71 \\
\hline $\begin{array}{l}\text { Number of teachers asking students to rewrite whole composition } \\
\text { without errors }\end{array}$ & 13 \\
\hline Number of teachers getting students to rewrite sentences only & 9 \\
\hline Number of teachers asking students to do re-corrections & 20 \\
\hline Number of teachers marking in red & 7 \\
\hline
\end{tabular}



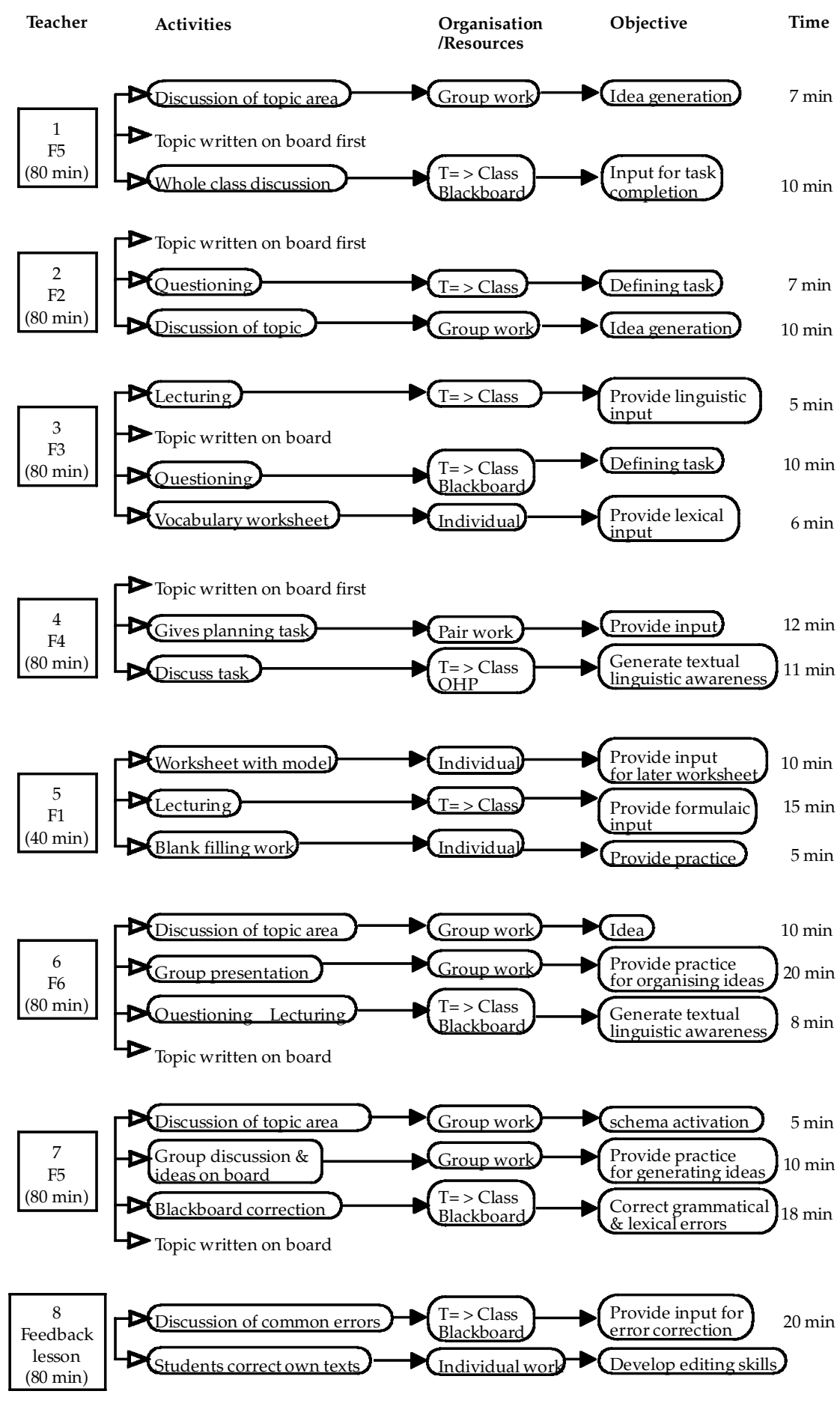

Figure A2 An overview of classroom practices observed 